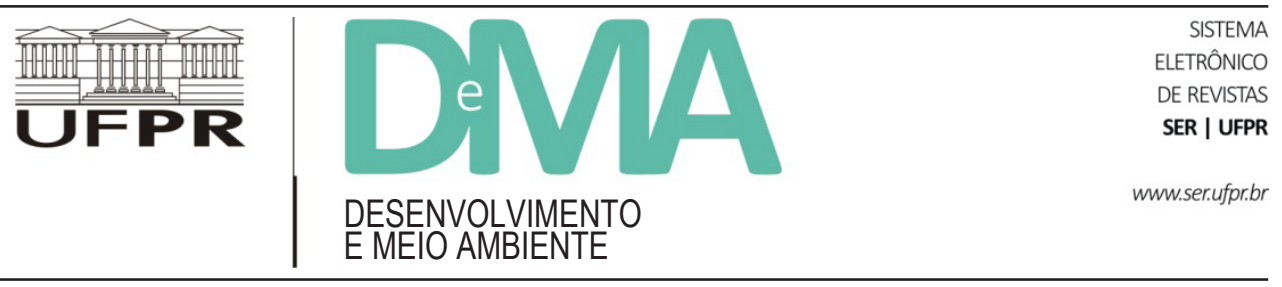

\title{
Ambiguidade de referenciais tecnológicos da ação pública no meio rural: agricultura familiar e limites à sustentabilidade
}

\section{Ambiguity of Public Action's Technological References in Rural Areas: Family Farming and Limits on Sustainability}

\author{
Adinor José CAPELLESSO ${ }^{*}$, Ademir Antonio CAZELLA², Oscar José ROVER² \\ ${ }^{1}$ Instituto Federal de Educação, Ciência e Tecnologia de Santa Catarina (IFSC), Campus São Miguel do Oeste, São Miguel do Oeste, SC, Brasil. \\ ${ }^{2}$ Universidade Federal de Santa Catarina (UFSC), Florianópolis, SC, Brasil. \\ *E-mail de contato: adinor.capellesso@ifsc.edu.br
}

Artigo recebido em 3 de outubro de 2015, versão final aceita em 14 de abril de 2016.

RESUMO: $\quad \mathrm{O}$ artigo analisa as políticas públicas específicas de crédito rural e seguro agrícola para a agricultura familiar com o objetivo de verificar suas compatibilidades com dois referenciais tecnológicos distintos: produtivista e agroecológico. Em termos metodológicos, um estudo de caso foi realizado na região Extremo Oeste de Santa Catarina, caracterizada pela presença de uma agricultura familiar socioeconomicamente dinâmica, com levantamento de dados junto a 37 unidades agrícolas familiares e 21 operadores locais de políticas públicas. As análises evidenciam uma dualidade na ação pública, que criou políticas voltadas para a agroecologia, mas que na operacionalização das políticas públicas analisadas prioriza o aumento da produtividade das unidades agrícolas familiares com alta dependência de insumos externos, em detrimento de considerar a rentabilidade por área e a valorização dos recursos locais. Concluímos que a ação pública tem limitado a adoção da agroecologia como paradigma tecnológico.

Palavras-chave: políticas públicas; agroecologia; crédito rural; seguro agrícola; autonomia.

ABSTRACT: The article analyzes the specific public policies of rural credit and agricultural insurance for family farms, it aims to check their compatibility with two distinct technological paradigms: productivist and agroecological. On methodology, a case study was conducted at the extreme western region of Santa Catarina. The data survey was composed by interviews with 37 family farmers and 21 local operators of public policies. This region is characterized by the presence of a family farm socioeconomic dynamics. The analysis reveals a duality in public action. In one hand, policies to agroecology were created. In other hand, the operation of those public policies analyzed, prioritizes the increasing productivity of family farming units with high dependence on external inputs, while disregards the profitability per area and the enhancement of local resources. We conclude that public action has limited the adoption of agroecology as a technological paradigm.

Keywords: public policy; agroecology; rural credit; agricultural insurance; autonomy. 


\section{Introdução}

O objetivo central deste artigo consiste em identificar os principais mecanismos operacionais das políticas públicas de crédito rural e seguro agrícola voltadas à agricultura familiar. Foram analisados o Programa Nacional de Fortalecimento da Agricultura Familiar (Pronaf) ${ }^{1}$ e o Seguro da Agricultura Familiar (SEAF) ${ }^{2}$, utilizando como recorte metodológico o estudo de caso, conduzido no Extremo Oeste catarinense. Trata-se de uma região de agricultura familiar dinâmica do ponto de vista socioeconômico e que apresenta estabelecimentos com produção orgânica ou em transição agroecológica ${ }^{3}$.

A amostra foi composta por 37 Estabelecimentos Familiares (EF) e dezoito operadores locais de políticas públicas nacionais. Os EF foram divididos em três grupos: a) um segmento especializado composto por sete produtores convencionais, que atuam em cadeias produtivas dinâmicas (suínos, aves, leite e grãos); b) um segmento composto por nove produtores orgânicos ou em transição agroecológica, com produção diversificada; e c) um grupo intermediário de $21 \mathrm{EF}$ convencionais, que se destacam pela diversidade de estratégias de reprodução social, com predomínio da atividade leiteira ${ }^{4}$. O levantamento de dados contou com entrevistas semiestruturadas, seguidas da transcrição e da análise de discurso. Os resultados foram triangulados com estudos técnico-econômicos que comparam sistemas de produção orientados pela agroecologia com sistemas convencionais.

$\mathrm{O}$ artigo está estruturado em cinco partes, além desta introdução. A segunda situa o quadro teórico mobilizado na análise cognitiva de políticas públicas. A partir desse enfoque teórico, a terceira parte diferencia os dois principais referenciais setoriais agropecuários que orientam a ação pública para a agricultura familiar. Em seguida, a quarta parte evidencia limites energéticos e econômicos da intensificação crescente no uso de insumos convencionais por parcela significativa de agricultores familiares da região de estudo. A quinta parte discute os resultados do estudo de caso e sua correlação com algumas normas do Pronaf e do SEAF, concebidas com base em ideias produtivistas que se chocam com características produtivas preconizadas pela agroecologia. Na sexta parte, as conclusões destacam que essas políticas públicas de caráter financeiro têm contribuído para o emprego crescente de insumos convencionais, enquanto persistem entraves operacionais das políticas para promover a adoção de sistemas orientados pela agroecologia.

\footnotetext{
${ }^{1}$ O Pronaf é uma política pública de crédito rural direcionada especificamente a agricultores familiares. Os recursos financeiros são acessados com taxas de juros inferiores aos praticados no mercado e devem ser aplicados na atividade produtiva especificada em contrato.

${ }^{2}$ O SEAF consiste em uma linha de seguro agrícola do Programa de Garantia da Atividade Agropecuária (Proagro) direcionada especificamente à agricultura familiar, também denominado "Proagro Mais". Essa linha opera com prêmio de 2\% do valor segurado, pago pelo agricultor, enquanto o Governo Federal aporta outros $6 \%$, totalizando $8 \%$ do valor enquadrado (Zukowski, 2012).

${ }^{3}$ No Brasil, a Lei 10.831/2003 adotou o termo "orgânico" para designar o conjunto de sistemas de produção de base ecológica. De forma resumida, as normativas legais para certificação de conformidade orgânica pró́bem o uso de fertilizantes solúveis de alta solubilidade (adubo químico), transgênicos, agrotóxicos, hormônios sintéticos e radiação ionizante. A isso se somam distintas normas destinadas à conservação dos recursos naturais, respeito ao bem-estar animal e dos trabalhadores (Brasil, 2003). Contudo, como se destaca mais adiante, os princípios da agroecologia podem ser adotados tanto por agricultores orgânicos como convencionais. Nesse caso, a transição agroecológica é adotada para designar estabelecimentos que passam a adotar tecnologias e práticas orientadas pela agroecologia, mesmo sem certificação de orgânicos. ${ }^{4}$ A caracterização das estratégias de reprodução social desses EF e uma análise de sua organização cooperativa para enfrentar as contradições da seleção excludente na cadeia do leite encontra-se em Capellesso \& Cazella (2015).
} 


\section{Referenciais para a construção de políticas públicas para a agricultura familiar}

A análise de políticas públicas ganhou força na Europa dos anos 1980 ao se explicar o Estado a partir de suas ações. Muller (2000) define esse campo de análise como uma sociologia da ação pública, mobilizando principalmente conceitos de atores, conhecimentos, poder, estratégia e informação. Seus estudos permitiram a renovação de uma série de questões relacionadas ao político, a começar pela natureza do poder político; a superação das visões de Estado como estrutura central na solução de problemas e como agente dominador que impõe a ordem política; os limites da racionalidade na ação pública; e, de forma mais ampla, que a representação via disputa eleitoral não é o único elemento explicativo das políticas públicas.

Apesar dos avanços gerados pela nova disciplina, ao explicar a sociedade global a partir do comportamento e estratégias dos atores sociais, Muller $(2000 ; 2013)$ destaca que muitas análises não dão conta do fato que o global transcende as estratégias individuais e coletivas. Essas análises desconsideram que os atores são, muitas vezes, constrangidos pela estrutura global, a qual limita as possibilidades e a liberdade da ação. Nessa direção, a abordagem cognitiva de políticas públicas (Muller, 2000) se propõe a incorporar as interferências das normas sociais globais dos atores (quadros de interpretação do mundo) na análise da ação pública, entendendo que as ideias mais gerais refletem nas decisões de políticas públicas específicas.
Dentre as várias abordagens ${ }^{5}$, o conceito de referencial remete à construção de quadros cognitivos de interpretação do mundo. Esses quadros configuram-se como representações que cada sociedade faz para compreender e agir nas situações reais. A partir de um referencial de realidade se constrói o "referencial de uma política pública", o que permite identificar o problema, confrontar soluções e orientar a ação. Os valores são a representação mais ampla e fundamental do que é bom ou mau; a ação da política pública é definida pela diferença entre o real observado e o real desejado, sendo a decisão orientada por relações causais (causa e efeito). O referencial é dividido em global - interpretação de mundo da sociedade em um determinado momento - e setorial - representação do setor segundo normas, valores, regras de funcionamento, papéis sociais e estrutura. A representação setorial mais coerente com a global seria a adotada como referencial na elaboração de políticas públicas (Surel, 1998; Muller, 2013).

A partir da classificação da análise cognitiva como uma abordagem pelas ideias, Muller (2000) destaca que a construção dos quadros cognitivos de interpretação do mundo incorpora também interesses e instituições ${ }^{7}$. A formulação e a articulação dos referenciais em um todo coerente fica a cargo dos mediadores, que podem ser representantes do Estado, academia ou atores sociais interessados. As políticas públicas são construídas e transformadas segundo essa relação global/setorial, no sentido de ajustar o setorial ao global toda vez que o global sofra mudanças. Contudo, na execução de

\footnotetext{
${ }^{5}$ Para diferenciações internas referentes a três abordagens cognitivas - paradigma, referencial e quadro de coalizão de causa - ver Surel (1998).

${ }^{6}$ A suposição de coerência entre níveis macro e micro é considerada uma debilidade das abordagens cognitivas, pois as ideias gerais nem sempre refletem nos níveis setoriais (Surel, 1998). Essa crítica é atenuada quando se considera que diferentes referenciais globais e setoriais disputam espaço na construção da ação pública, a exemplo do que ocorre em torno dos modelos de agricultura convencional e da agroecologia. ${ }^{7}$ Essa afirmação busca responder a crítica advinda do neoinstitucionalismo, que defende a integração de ideias, interesses e instituições na análise de políticas públicas (Hall \& Taylor, 2003; Palier \& Surel, 2005). Muller (2000) considera que a abordagem cognitiva contempla as instituições e interesses.
} 
políticas públicas, os resultados esperados podem ser afetados pela adoção de referenciais distintos entre os mediadores administrativos (elaboradores da política) e mediadores profissionais (executores nos espaços locais).

Assim, a abordagem cognitiva busca identificar as diferentes representações da realidade sobre as quais o "problema político" se relaciona: os referenciais da política pública que organizam as percepções dos atores sobre a situação, a confrontação de soluções e a definição de suas propostas e ações. A construção desses referenciais geralmente está permeada por interesses contraditórios no quadro dinâmico da sociedade, surgindo conflitos de paradigmas que perduram por algum período até que um se torne hegemônico, mas não único (Muller, 2013).

Ao analisar os processos de mudanças de orientação nas políticas públicas, Surel (1998) aponta que a penetração de um novo referencial normalmente não ocorre de forma revolucionária. Dois filtros interagem nesse processo: a) a importância e as características próprias do referencial anterior que, em vez de substituição, promovem uma adaptação do antigo ao novo, ocorrendo associação e hierarquização dos novos elementos com os anteriores; e b) as configurações institucionais específicas, que mobilizam os interesses dos atores, suas instituições e relações de poder, alterando a nova matriz normativa e cognitiva. Esse parece ser o caso da incorporação da agroecologia na ação pública brasileira, pois ocorre de forma gradual, via novas políticas públicas e sem alterar de forma contundente as anteriores que lhes são contraditórias. A atuação dos filtros explica outra ausência de ruptura relacionada à disputa de referenciais setoriais das políticas públicas. No meio rural, as décadas de 1980 e 1990 marcam a ascensão de movimentos sociais que conferem capacidade de representação na esfera pública de interesses outrora desconsiderados (Sabourin, 2007). Sem deixar de apoiar os tradicionais beneficiários de políticas públicas, o Brasil passou a ser um dos poucos países do mundo a adotar uma definição de "agricultor familiar" na operacionalização da ação pública. Os beneficiários dessas políticas públicas específicas são agricultores que, concomitantemente, exploram estabelecimentos agropecuários com até quatro módulos fiscais ${ }^{8}$, administram e trabalham de forma predominante com sua família, obtendo a maior parte de sua renda familiar das atividades econômicas provenientes do estabelecimento. A legislação brasileira inclui na noção de agricultura familiar, também, os agricultores assentados pela política de reforma agrária, pescadores artesanais, quilombolas, extrativistas e comunidades indígenas (Brasil, 2006; 2011).

Na relação estabelecida com os quadros cognitivos globais de sociedade, o referencial setorial dominante no agro brasileiro pode ser denominado "produtivista", visto que a intensificação é orientada ao aumento de produtividade. Embora essa seja defendida como caminho para alcançar maior lucratividade, tal resultado nem sempre se efetiva. Para enfrentar as contradições dessa proposta tecnológica, agricultores e profissionais das ciências agrárias criaram uma série de iniciativas produtivas, sendo que muitas delas se articularam em torno de um outro referencial denominado "agroecológico". Como se verá a seguir, embora esse novo referencial tenha menor poder econômico, seu apelo social e ambiental se articula com as demandas

\footnotetext{
${ }^{8}$ A Lei n ${ }^{\circ} 6.746$, de 1979, definiu o módulo fiscal como área mínima para viabilizar economicamente uma unidade produtiva em dado município, constituindo-se em uma média calculada com base nas explorações e rendas obtidas por meio delas. No Extremo Oeste catarinense, região do estudo de caso, o módulo fiscal varia entre 18 ha e 20 ha.
} 
contemporâneas por sustentabilidade ${ }^{9}$ e confere aos atores legitimidade para disputar espaço com o produtivismo na formulação e na operacionalização da ação pública.

\section{Reconstrução da trajetória dos referenciais tecnológicos de agricultura}

A segunda revolução agrícola dos tempos modernos ${ }^{10}$, mais conhecida como Revolução Verde, caracterizou-se pelo fomento de sistemas produtivos baseados em tecnologias mutuamente dependentes (pacotes tecnológicos), compostas por variedades geneticamente melhoradas para responder a altas doses de fertilizantes solúveis de síntese química industrial, conduzidas em monoculturas mecanizadas de larga escala e protegidas por agrotóxicos ${ }^{11}$. Nos sistemas de criação animal, sua expressão se dá pela seleção genética voltada a obter melhores índices de conversão alimentar, ampliação da escala produtiva via confinamento e uso de produtos químicos (especialmente antibióticos) para compensar a perda de rusticidade ou aumentar a produtividade (Mazoyer \& Roudart, 2010). Em todos os países em que foi adotada, a modernização técnica produtivista foi impulsionada pelo expressivo aporte de recursos públicos.

No Brasil, a criação de políticas públicas destinadas a promover esse tipo de modernização se intensificou durante a segunda metade do século
$\mathrm{XX}$, tendo como beneficiários prioritários os proprietários de grandes extensões de terras. Quando incorporava agricultores familiares, especialmente no Sul e Sudeste do país, os induzia para o processo excludente dos ganhos de escala, que ocorreu tanto na mecanização de monoculturas agrícolas quanto nas criações animais via integração vertical com as agroindústrias - tendo como exemplos clássicos os casos da suinocultura e da avicultura (Capellesso \& Cazella, 2015). A defesa desse modelo se justificava pela necessidade de aumentar a produção de alimentos diante da crescente demanda alimentar (Odum, 1988), tornar a agricultura um espaço lucrativo para o capital (Delgado, 1985), acabar com a pobreza rural (Schultz, 1965) e liberar mão de obra para os centros urbanos (Graziano da Silva, 1982). Enquanto os questionamentos sociais e ambientais a esse modelo ganhavam força no final da década de 1970, a contracrítica apontava para a falta de alternativas concretas, justificando as contradições da modernização como um "mal necessário".

A necessidade de demonstrar que era possível construir um modelo alternativo deu origem, no Brasil, a uma série de experiências embrionárias a partir da década de 1980. Em alguns casos, essas experiências buscavam combater a exclusão social pela adaptação dos "pacotes tecnológicos" ao contexto da agricultura familiar. Já em outros, a construção de sistemas de produção mais sustentáveis se afastava do modelo convencional,

\footnotetext{
${ }^{9}$ Como toda a ação gera alguma degradação de recursos naturais, não se pode adotar o dualismo entre ser ou não ser, pois nenhuma atividade seria sustentável. A questão está mais relacionada aos níveis entre os polos, atendendo mais ou menos os preceitos da sustentabilidade.

${ }^{10}$ A agricultura ocidental já havia passado por importantes momentos evolutivos, como a descoberta da rotação bienal de culturas e a tração pesada (arado charrua) entre os séculos XI e XIII. Contudo, Mazoyer \& Roudart (2010) consideram que a primeira revolução agrícola dos tempos modernos ocorreu somente ao longo dos séculos XVIII e XIX. Nessa ocasião, o aspecto revolucionário residiria na ampliação da rotação para a escala trienal, sendo o pousio substituído pelas forrageiras e criações. Além de produzir alimentos e força de trabalho, os animais auxiliam no controle de plantas invasoras e deixam no solo grande volume de fertilizantes orgânicos, contribuindo para o aumento da produção e da produtividade.

${ }^{11}$ Como exemplo da opção por esse tipo de modelo produtivo no Brasil, destaca-se a isenção de impostos na comercialização de agrotóxicos, a qual persiste até os dias atuais.
} 
eliminando principalmente os agrotóxicos. Muitas experiências voltadas a adaptar os "pacotes" ao contexto da agricultura familiar enfrentaram limites insolúveis, visto que esse segmento se encontrava, na época, descapitalizado e amplamente excluído das políticas públicas de crédito rural subsidiado.

Por articular críticas ao modelo produtivista com ações práticas, esse movimento ficou conhecido, inicialmente, como "agricultura alternativa". Caracterizado pela diversidade e sendo ressignificado em suas metamorfoses, outras denominações lhe foram atribuídas, como "agricultura ecológica", "agricultura sustentável" e, mais recentemente, "agroecologia". Além dessas, incorporou nomes de correntes de agriculturas de base ecológica criadas em outras partes do mundo (biodinâmica, biológica, natural, permacultura, orgânica, regenerativa e de baixo uso de insumos). Como se trata de um processo dinâmico e em construção, tais correntes atendem, em muitos pontos, os preceitos econômicos, sociais e ambientais da sustentabilidade ${ }^{12}$ (Bonilla, 1992; Primavesi, 1997; Caporal \& Costabeber, 2002).

A partir da década de 1990, os distintos movimentos que compõem essas iniciativas ampliaram suas conexões com a pesquisa. Nessa direção, embora a defesa da sustentabilidade venha sendo gradativamente incorporada no meio científico, as análises sobre a agroecologia divergem quanto à sua capacidade transformadora. Do lado dos posicionamentos críticos, Navarro (2013) questiona sua base científica, considerando-a uma ideia fantasiosa e inviável diante da eficiência do agronegócio. Essa afirmação encontra respaldo na baixa adesão de agricultores aos sistemas de produção orientados pela agroecologia. Como um indicador desse fenômeno, os dados do Censo Agropecuário de 2006 apontam que apenas 90.497 estabelecimentos brasileiros, $1,75 \%$ do total nacional, se declararam praticantes da agricultura orgânica. Entre esses, a imensa maioria não apresentava certificação de conformidade orgânica por entidade credenciada, restrita a 5.106 estabelecimentos $-0,1 \%$ do total nacional (IBGE, 2009) ${ }^{13}$. Se a baixa presença de estabelecimentos que adotam a produção orgânica traz indícios da dificuldade para avançar, isso não justifica as contradições do modelo estabelecido. $\mathrm{Ou}$ seja, a aparente eficiência econômica do agronegócio identificada por Navarro (2013) desconsidera os elevados subsídios públicos e oculta os custos nas demais dimensões da sustentabilidade, especialmente ambientais e socioculturais.

Reiterando a necessidade de alternativas concretas frente às contradições do modelo convencional, Almeida (2002, p. 37) questiona o sectarismo político presente em iniciativas de fomento

\footnotetext{
${ }^{12}$ Para Caporal \& Costabeber (2002), a agroecologia inclui ainda as dimensões ética, política e cultural, que não serão abordadas diretamente neste estudo. Segundo esse entendimento, poderíamos falar em sustentabilidades. Contudo, optou-se por manter o termo no singular para evitar mais confusões em torno de um conceito que já é extremamente polissêmico. Para uma reconstrução da trajetória das ideias globais de sustentabilidade, ver Veiga (2010).

${ }^{13}$ Deve-se considerar que os dados do censo são declaratórios, não se tratando de uma classificação ex post a partir das características verificadas no sistema produtivo. Esses percentuais podem apresentar, portanto, distorções para mais ou para menos. Sendo assim, o baixo número de agricultores que se declara orgânico contrasta com o elevado número de estabelecimentos que adotam técnicas compatíveis com essa classificação. O Censo Agropecuário de 2006 aponta, por exemplo, que aproximadamente $70 \%$ dos estabelecimentos agropecuários não utilizaram agrotóxicos e adubos químicos de alta solubilidade. Contudo, técnicas e insumos preconizados pela agroecologia têm baixa expressão: adubação com esterco animal (12,1\%), adubação verde (2,7\%), composto orgânico (2,5\%), inoculantes biológicos $(0,68 \%)$, biofertilizantes $(0,42 \%)$ e húmus de minhoca $(0,07 \%)$ (IBGE, 2009).
} 
à agroecologia e defende a necessidade de disputar o campo $^{14}$ científico como base para "subsidiar/sustentar a luta no campo político e social mais amplo". A partir dos conceitos de disputa paradigmática, Caporal et al. (2006) e Petersen (2013) caracterizam a agroecologia enquanto ciência interdisciplinar, que lança olhares interconectados sobre o espaço rural. Ao buscar entender melhor os problemas inerentes às práticas agrícolas atualmente adotadas, a agroecologia propõe, aplica e avalia inovações técnicas, com a finalidade de contribuir para a ampliação da sustentabilidade, nas suas diversas dimensões. Nesse entendimento, a agroecologia representa a tentativa de incorporação científica da sustentabilidade na agropecuária, não devendo ser confundida como um mero sistema de produção.

Para Gliessman (2000), as ações de transição agroecológica dos sistemas produtivos podem ocorrer em três níveis, não necessariamente sequenciais: a) aumento da eficiência no uso de insumos e técnicas convencionais; b) substituição desses insumos e técnicas; e c) redesenho dos agroecossistemas. Em trabalho posterior, Gliessman et al. (2007) incorporam um quarto nível: a mudança de ética e de valores para uma cultura da sustentabilidade. Esses autores aproximam-se, assim, das concepções multidisciplinares, segundo as quais a agroecologia perpassa a condição de paradigma científico tecnológico das ciências agrárias e se converte em processo de mudança social global. Nesses termos, pode-se apontar que ideias originadas em setores específicos podem interagir com os referenciais globais de sociedade portados pelos indivíduos
(Muller, 2000), existindo uma retroalimentação dialética entre o setorial e o global.

$\mathrm{O}$ presente trabalho entende a agroecologia como um campo de investigação científica multidisciplinar que busca converter a agricultura atual em formas mais sustentáveis de produção, não necessariamente enquadradas na legislação brasileira de conformidade orgânica (Caporal \& Costabeber, 2004). Nesse caso, a agricultura orgânica tem dois significados. O primeiro se refere a um sistema de produção de base ecológica proposto por Howard (2007), baseado no emprego de fertilizantes orgânicos e promoção da vida no solo. O segundo resulta da adoção de tal termo pela legislação brasileira de conformidade orgânica, que estabelece as normas comuns a serem cumpridas pelos distintos sistemas produtivos de base ecológica, para que se possa vender os alimentos certificados como "orgânicos". Para além dos termos normativos da legislação de produção orgânica, a agroecologia busca promover a adoção de técnicas que atendem aos preceitos da sustentabilidade, tanto na produção convencional como na orgânica.

A incorporação da sustentabilidade no referencial global e nas disputas políticas contribuiu para o reconhecimento da agroecologia em algumas esferas do Estado brasileiro. Contudo, a capacidade de intervenção na ação pública tem sido pouco efetiva, com caráter pontual e subordinado às concepções anteriores. Para Petersen (2013), a agroecologia representa uma opção necessária para a superação do referencial produtivista no âmbito das políticas públicas para a agricultura familiar. Tendo por base

\footnotetext{
${ }^{14}$ A análise de Almeida (2002) mobiliza o conceito de campo de Bourdieu, que se refere a um recurso metodológico para interpretar um espaço social com estrutura própria. Nesse espaço se trava uma luta concorrencial entre os atores, decorrente de relações de poder existentes em seu interior e da distribuição desigual do tipo de capital dominante em cada campo. Inicialmente autônomos, os campos se relacionam entre si, sendo que um pode subsidiar o outro nas disputas em jogo.
} 
teórica o neoinstitucionalismo, esse autor destaca a dificuldade para as inovações institucionais nesse campo específico:

Prisioneiras de uma prática operacional e de uma estrutura funcional concebidas segundo o paradigma da modernização, as instituições públicas encontram dificuldades de escapar de rotinas que as mantêm fortemente atreladas ao viés do produtivismo economicista, aos postulados epistemológicos positivistas e ao seu corolário metodológico, o difusionismo (p. 69).

Esse parece ser o quadro de algumas políticas públicas direcionadas à agricultura familiar, especialmente o Programa Nacional de Fortalecimento da Agricultura Familiar e o Seguro da Agricultura Familiar. Embora o Pronaf possua uma linha de financiamento destinada à "agroecologia", dados empíricos apontam para a dificuldade de essa política pública contemplar operacionalmente as especificidades de custeio dos agricultores orgânicos. Esse quadro é mais grave no caso da cobertura do seguro agrícola, que é operado em conjunto com o custeio agrícola do Pronaf ${ }^{15}$. Essas limitações parecem decorrer das concepções produtivistas reproduzidas no crédito rural, direcionado principalmente para adquirir insumos "modernos", o que reforça o modelo produtivo convencional (Capellesso et al., 2016).

Entre os agricultores beneficiados pelo Pronaf, a maioria adota sistemas de produção convencional. No caso do custeio, o financiamento subsidiado contribui com a redução nos custos financeiros de recursos utilizados para aquisição de insumos. Já o seguro agrícola, operado em conjunto com o Pronaf custeio agrícola, externaliza ${ }^{16}$ os riscos econômicos de sua aplicação. Isto altera a racionalidade dos investimentos, com menor atenção à eficácia e à efetividade dos sistemas produtivos e maior ênfase aos recursos financeiros de facilitado acesso destinados à compra de insumos externos. Como já destacava Schultz (1965), considerado um dos mentores teóricos da Revolução Verde, o agricultor avalia a adoção de um novo fator de produção pela relação entre as possibilidades de lucro com os riscos e incertezas de seu uso.

No caso do SEAF, ao estimular a adoção dos fatores de produção que são segurados diante de eventuais perdas, essa política pública tende a contribuir com a intensificação de sistemas produtivos com eficiência econômica questionável e impactos ambientais relevantes. Ou seja, enquanto setores da sociedade incorporam a defesa da sustentabilidade, sobretudo ambiental, e estudos consideram a agricultura familiar como "lócus ideal" para efetivá-la no espaço rural (Do Carmo, 2008), políticas públicas específicas para esse segmento social têm estimulado a adoção de sistemas produtivos com níveis tecnológicos que seguem em sentido oposto.

Dada a importância da ação pública na definição dos modelos de agricultura e, especialmente, para a superação do paradigma da modernização, Petersen (2013) aponta para a necessidade de construir um campo de estudo que busque superar a dificuldade de desenhar "políticas públicas orientadas à

\footnotetext{
${ }^{15}$ Somente no Plano Safra 2014/15 foi criada a linha de financiamento de custeio para a agroecologia, antes restrita à modalidade investimento para transição agroecológica. A isso se soma a promessa de oferta de Assistência Técnica e Extensão Rural (ATER) para 120 mil produtores agroecológicos do país.

${ }^{16}$ Em termos práticos, a existência do seguro agrícola não reduz o risco da atividade ser impactada pelo sinistro ao qual o seguro oferece cobertura. O que ocorre é a transferência do risco do agricultor para um sistema de gerenciamento. No caso do SEAF, a sua viabilidade é mantida predominantemente com recursos públicos. Logo, optou-se por caracterizar esse seguro como uma forma de externalização dos riscos do agricultor ao conjunto da sociedade. Contudo, esse entendimento não nega a possibilidade de vincular ao seguro agrícola normas que orientem a adoção de sistemas com menor suscetibilidade às perdas.
} 
promoção da sustentabilidade da agricultura e, em escopo mais amplo, dos sistemas agroalimentares" (p. 98). Para o autor, esse processo passa pela valorização da agricultura familiar como protagonista do desenvolvimento rural, permitindo a "superação do paradigma da modernização na esfera das instituições públicas" (p. 98). Para alcançar esse objetivo, entende ser necessária a articulação entre a academia (ciência com base na teoria crítica), a prática social (coerente com a teoria agroecológica) e os movimentos sociais (agricultores, movimentos, organizações e demais atores envolvidos).

Ao partir do pressuposto de que a ação pública poderia contribuir com a adoção de práticas mais sustentáveis (ex.: redução do uso de agrotóxicos, valorização da fertilidade dos agroecossistemas, inclusão social), Petersen (2013) propõe que as políticas públicas sejam (re)desenhadas com vistas a contemplar um conjunto mais amplo das dimensões da sustentabilidade. Para oferecer suporte a essa proposta, o próximo tópico analisa limites ambientais e econômicos das políticas públicas à luz da distinção interna da agricultura convencional e orgânica. Para isso, se discutirá o estudo de caso conduzido em estabelecimentos familiares localizados na região Oeste do Estado de Santa Catarina.

\section{Agricultura familiar: contradições da intensificação no uso de insumos}

A análise comparativa de áreas de milho em sistemas de produção orgânico e convencional (transgênicos e não transgênicos) em estabelecimentos agrícolas familiares demonstrou grandes diferenças no uso de insumos e na Eficiência
Energética $(\mathrm{EE})^{17}$. As elevadas entradas de energia são um indicador da intensificação no uso de insumos, especialmente de origem industrial. $\mathrm{Na}$ média de duas safras analisadas, os sistemas de produção convencionais de milho transgênico e não transgênico utilizaram, respectivamente, 7,3 e 5,5 vezes mais energia por unidade de área que o sistema orgânico. Essa intensificação nas entradas reflete negativamente sobre a EE. Enquanto a produção orgânica alcançou média de 28,3 unidades de energia produzidas por unidade aplicada, as EE na produção convencional de milho transgênico e não transgênico foram, respectivamente, de 5,0 e 6,1 , ou seja, menos de $25 \%$ da produção orgânica (Capellesso \& Cazella, 2013).

Ao diferenciar as fontes de energia, verifica-se que a de origem fóssil representou mais de $80 \%$ do total de insumos empregados na produção convencional, sendo os fertilizantes nitrogenados de síntese química industrial responsáveis por mais da metade da energia total empregada nesses sistemas. Em paralelo, os cultivos de milho conduzidos em sistema orgânico registraram menor quantidade absoluta e relativa de energia não renovável (menos de $35 \%$ ), alcançando maior EE. Tendo por base esse indicador energético, a produção de variedades de milho de polinização aberta em sistema orgânico foi ambientalmente mais sustentável que os sistemas convencionais de milho híbrido transgênico e não transgênico (Capellesso \& Cazella, 2013).

Junto aos limites ambientais, Capellesso et al. (2016) demonstram que o referencial produtivista assenta seu retorno econômico na escala (aumento da área) e não na maior rentabilidade por unidade de área. Para isso, os autores realizaram cálculo

\footnotetext{
${ }^{17}$ A EE é calculada pela divisão entre a quantidade de energia obtida na produção e a energia utilizada no sistema produtivo. Para isso, todas as saídas e entradas são convertidas em energia. Quanto maior o cociente, maior a EE. No caso da EE fóssil, divide-se a saída total pela entrada de origem fóssil. No caso da EE total, o denominador inclui todas as entras (Pimentel et al., 2005).
} 
comparativo considerando duas safras de milho e os seguintes quesitos: a) entradas; b) saídas; c) preços de mercado; e d) produção obtida (Tabela 1). Os resultados refutam o referencial produtivista de que "produzir mais é melhor", havendo rentabilidade média equiparável por unidade de área entre os sistemas com diferentes produtividades. Ao incluir o preço premium $^{18} 30 \%$ superior, pago aos produtores orgânicos por esse diferencial de qualidade, não houve diferenças estatísticas na margem bruta média por hectare. Embora com menor produtividade, o valor agregado ${ }^{19}$ médio foi superior nos sistemas menos intensivos em insumos industriais. Ou seja, mesmo obtendo maior produtividade, o aumento nos custos de produção dos sistemas convencionais comprometeu a margem bruta, sendo essa superior somente em anos ambientalmente favoráveis. Como relata um profissional técnico entrevistado:

TABELA 1 - Margem bruta $^{1}$ e valor agregado ${ }^{2}$ médio em sacas ha-1 ${ }^{-1}$ para três sistemas de produção de milho na região Extremo Oeste catarinense - Safra 2011/12 com escassez hídrica; e estimado com base na Safra 2010/11, de ótima distribuição de chuvas.

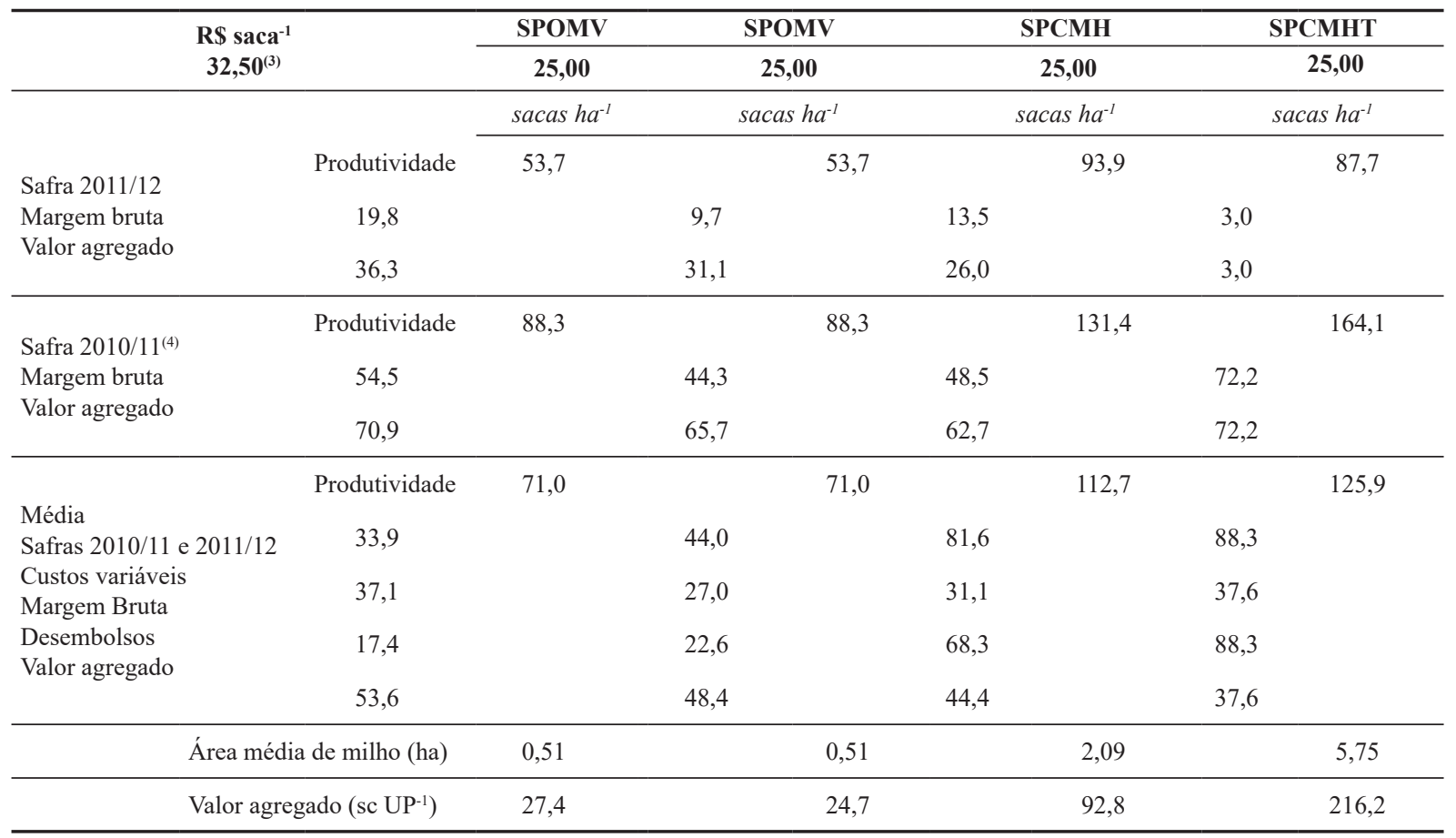

Legenda:SPOMV: Sistema de produção orgânico de milho variedade de polinização aberta. SPCMH: Sistema de produção convencional de milho híbrido. SPCMHT: Sistema de produção convencional de milho híbrido transgênico. sc $\mathrm{UP}^{-1}$ : sacas por unidade produtiva. Notas: ${ }^{(1)}$ margem bruta $=$ receita bruta - custos variáveis. ${ }^{(2)}$ valor agregado $=$ receita bruta - desembolsos. ${ }^{(3)}$ preço premium $30 \%$ superior, conforme recebido pelos produtores orgânicos. ${ }^{(4)}$ calculada com base nos custos da safra 2011/12 e colheita obtida na safra $2010 / 11$, que contou com ótima distribuição de chuvas.

FONTE: Adaptado de Capellesso et al. (2016).

\footnotetext{
${ }^{18}$ Esse preço premium se dá por meio da valorização da qualidade na venda de produtos, a exemplo do acesso a mercados organizados por cooperativas de produtores orgânicos.

${ }^{19}$ Valor agregado é a diferença entre a receita bruta e custos que representam desembolsos monetários. Já para a margem bruta descontam-se da receita bruta todos os custos variáveis.
} 
[Tu tens uma dimensão de custos que está dando em uma área para produção de 200 sacas de milho?] $A h$, dá em torno de 120 sacas, por aí. [De custo?] De custo. [Sobraria uns 80?] É, nessa faixa aí, de 60 a 80 sacas. [O problema é se tu tens um ano com seca?] Dai tu pega um ano de seca que nem esse aqui [Safra 2013/2014], quem plantou bem cedo colheu. Nós tivemos agricultores de 217, 213. Atrasou um pouquinho o plantio, 120, 115. [Aí empata?] Empata (OP 12).

Em termos técnico-produtivos e econômicos, a produção orgânica propiciou níveis de produtividade intermediários e em áreas menores. Para isso, foram mobilizados fatores produtivos provenientes do estabelecimento familiar, aos quais se somam alguns insumos de baixo custo adquiridos nos mercados, a exemplo de cama de aviário e sementes de variedades de polinização aberta. Os menores custos desembolsáveis representam um afastamento em relação aos mercados de insumos convencionais. Embora com produtividades inferiores, quando comparadas aos sistemas convencionais, o sistema de produção de milho orgânico assenta seu retorno econômico nos menores custos e preços $30 \%$ superiores. Já a produção de milho convencional (transgênico e não transgênico) é conduzida em sistemas intensivos de insumos industriais. Embora essa tecnologia propicie maior produtividade e ampliação da escala, os elevados custos corroem a rentabilidade econômica por área.

Destaca-se que essa análise econômica não considerou as rendas provenientes do seguro agrícola e o cálculo se deu com base na média entre uma safra com ótima distribuição de chuvas (2010/11) e outra com escassez hídrica (2011/12). Considerando os referenciais de agricultura discutidos anteriormente, pode-se apontar que os sistemas de produção convencionais analisados se assentam no "produtivismo modernizante". Sua viabilidade se perpetua graças, sobretudo, a duas políticas públicas: a) o Pronaf, que propicia o acesso a recursos subsidiados para a ampliação da escala; e b) o $\mathrm{SEAF}$, que externaliza os riscos econômicos ${ }^{20}$. Por sua vez, a produção orgânica ocorre em contextos de diversificação produtiva (número maior de atividades em áreas menores) e elevação do valor agregado (Capellesso et al., 2016). Dessa forma, consegue-se enfrentar um risco menor diante do quadro de exclusão da produção orgânica na operacionalização do SEAF.

Em outro estudo de caso sobre a produção de leite, realizado na região Oeste Catarinense, Lorenzon (2004) comparou sistemas com alimentação à base de pasto com aqueles que intensificam a produção via fornecimento de ração no cocho. A diferença fundamental entre esses dois sistemas é que o primeiro prioriza o pastoreio direto, enquanto o segundo utiliza-se de equipamentos para colheita, conservação e fornecimento de alimentos no cocho. Os EF com produção de leite à base de pasto tiveram custos totais de $\mathrm{R} \$ 0,37$ por litro $\left(\mathrm{l}^{-1}\right)$, enquanto a alimentação no cocho (confinamento) resultou em $\mathrm{R} \$ 0,43 \mathrm{l}^{-1}$. Na sua composição, os custos variáveis foram de $\mathrm{R} \$ 0,17 \mathrm{1}^{-1}$ para produção a base de pasto e $\mathrm{R} \$ 0,32 \mathrm{1}^{-1}$ para alimentação no cocho, sendo esse último $88,2 \%$ maior. Segundo o autor, o principal componente dessa diferença é a alimentação (60\% do valor), com destaque para o fornecimento de concentrado (geralmente com desembolso) e silagem (produção intensiva de milho convencional, de custo elevado). Embora com investimentos em instalações maiores, o sistema com alimentação

\footnotetext{
${ }^{20}$ A existência do seguro agrícola não reduz o risco da atividade ser impactada pelo sinistro ao qual o seguro oferece cobertura. O que ocorre é a transferência do risco do agricultor para um sistema de gerenciamento. No caso do SEAF, a sua viabilidade é mantida predominantemente com recursos públicos. Ou seja, externalizando os riscos do agricultor ao conjunto da sociedade.
} 
no cocho faz uso mais intensivo dos meios de produção (estruturas e equipamentos), resultando em menor custo fixo quando comparado ao sistema à base de pasto.

Com orientação produtivista, os EF com sistemas produtivos mais intensivos obtiveram maior produtividade por área e por vaca, mas ela não refletiu em rentabilidade. No sistema com alimentação no cocho, a produtividade média ao ano foi de $9.5241 \mathrm{ha}^{-1}, 5.0381 \mathrm{vaca}^{-1} \mathrm{e} 63.1821$ trabalhador $^{-1}$. Já no sistema à base de pasto, essas médias anuais foram de $3.9491 \mathrm{ha}^{-1}, 3.3901 \mathrm{vaca}^{-1} \mathrm{e}$ 35.5261 trabalhador $^{-1}$. Embora produzindo mais, a renda líquida por área ocupada (receita bruta total menos custo total) não diferiu estatisticamente entre os dois sistemas - média de $\mathrm{R} \$ 751,81 \pm 582,70$ $\mathrm{ha}^{-1}$ nas unidades com sistema à base de pasto $\mathrm{e}$ $\mathrm{R} \$ 678,50 \pm 445,78 \mathrm{ha}^{-1}$ para o sistema confinado. Por sua vez, a rentabilidade por vaca foi maior na produção à base de pasto. A explicação para esse resultado está no fato de a produção de leite à base de pasto ter custo médio por litro $16,2 \%$ menor e obter rendas extras do leite (Lorenzon, 2004) ${ }^{21}$.

Ao analisar os desembolsos, Lorenzon (2004) verificou que o custo do litro de leite à base de pasto gerava desembolsos médios de $\mathrm{R} \$ 0,17 \mathrm{1}^{-1}$, enquanto que no sistema com alimentação no cocho era de $\mathrm{R} \$ 0,32 \mathrm{l}^{-1}$. Verifica-se assim que a participação dos custos que geram saída monetária da unidade produtiva é bem menor no sistema à base de pasto $\left(\sim 50 \%\right.$ do custo $\left.{ }^{-1}\right)$ quando comparado ao sistema confinado $(\sim 75 \%)$. Essa diferença traz indícios da importância de otimizar o uso de insumos externos em sua associação com os fatores internos da unidade de produção, com destaque para a alimentação principal fator de custos na atividade leiteira. Dessa forma, a renda líquida por litro de leite produzido foi duas vezes maior no sistema à base de pasto ( $\mathrm{R} \$ 0,37 \mathrm{1}^{-1}$ contra $\mathrm{R} \$ 0,18 \mathrm{1}^{-1}$ ), o que compensou a menor produtividade ${ }^{22}$.

De forma semelhante ao verificado com a produção de milho, ao valorizar os recursos locais, a produção de leite à base de pasto possibilita a produção a baixo custo e renda equiparável aos sistemas mais intensivos. Por sua vez, a intensificação com alimentação no cocho eleva os riscos frente às oscilações de mercado, tanto para o preço dos insumos (especialmente concentrado e silagem) quanto em relação à queda no preço do leite. Como relata o responsável pelo EF 15, entrevistado neste estudo:

Até quatro meses atrás nós estávamos dando, na média, 1.500 a 2.000 quilos de concentrado por mês para as vacas. Nós vimos que não compensa isso aí. Diminuiu a produção, mas não chega ao fim do mês com aquele custo alto. O que eu puder fazer da minha lavoura e botar aqui. [Usa só o milho?] Isso. [Chega comprar farelo de soja?] Muito pouco. Às vezes eu compro, às vezes não. [...] Nós comprávamos concentrado. Até vinha o caminhão a granel e tudo. Fiz as contas. Em quatro meses come um mês de leite. Então diminui a produção, [pois] aumentou o preço [do concentrado], eu decidi cortar. [Cortou total?] Eu cortei uma boa parte (EF 15).

Este estudo reforça o argumento de que a rentabilidade dos sistemas mais intensivos em insumos se assenta na escala (área) e não na elevação da rentabilidade por área. De forma mais con-

\footnotetext{
${ }^{21}$ Essas rendas extras referem-se especialmente à venda de animais, tanto adultos como bezerros. Embora a analogia com a cultura do milho continue atual, o estudo de Lorenzon (2004) apresenta uma defasagem histórica de dez anos, impedindo a comparação em valores absolutos. Destaca-se ainda que o valor recebido por litro, na época, não diferiu entre as propriedades. Como demonstram Capellesso \& Cazella (2015), atualmente há casos em que as empresas pagam até 50\% a mais por litro a agricultores que detêm maior escala.

${ }^{22}$ O cálculo que Lorenzon (2004) denomina "renda líquida" (receita bruta menos desembolsos) se aproxima do que Ploeg (2006) denomina de "valor agregado", como mobilizado neste estudo.
} 
tundente, ao analisar o processo de intensificação na produção leiteira em países da Europa, Ploeg (2006) conclui que o uso intensivo de tecnologias e insumos refletiu em redução do valor agregado por área. Naquele caso, a presença de menor número de famílias (concentração da área e mecanização) permitiu aos remanescentes obter maior renda por unidade produtiva e trabalhador, mas gerando uma riqueza menor na região.

Diante das contradições inerentes ao preço diferenciado por critérios de escala, Capellesso et al. (2016) demonstram que a organização dos atores em cooperativas de comercialização permitiu postergar a exclusão de EF da cadeia do leite na região Extremo Oeste catarinense. Para Ploeg (2006; 2008), a organização e o distanciamento em relação ao mercado de insumos, a exemplo da busca de substitutos locais ou da redução no seu emprego, podem ser considerados estratégias mobilizáveis mesmo entre agricultores mais integrados aos mercados. A sua viabilidade prática fica condicionada à margem de manobra diante da integração ao mercado, a qual é delimitada pelos contextos à montante e à jusante. Junto a isso se deve considerar que o uso intensivo de insumos ocasiona sérios problemas ambientais, além de se assentar na dependência de recursos públicos.

Evidenciam-se assim dois referenciais que poderiam ser adotados na ação pública para ampliar a renda das famílias agricultoras: a) a ampliação de escala de cultivo em sistema convencional intensivo; ou b) produtividade intermediária de baixo custo e diversificada, associada à valorização do produto via diferenciais de qualidade (ex. orgânico) (Wilkinson, 2008). Entre os polos da dualidade de referenciais tecnológicos convencional e agroecológico, os agricultores familiares mesclam essas estratégias técnico-econômicas de acordo com as opções tecnológicas e as possibilidades criadas pelas políticas públicas.

O referencial convencional tem sido viabilizado com a aplicação de recursos públicos via, sobretudo, Pronaf e SEAF. Junto com o Pronaf, que garante o capital de giro a baixo custo, a operacionalização do seguro agrícola permite contornar riscos que antes restringiam a integração ao mercado de insumos. Excluídos do seguro agrícola, os produtores orgânicos buscam diminuir os custos desembolsáveis pelo emprego de fatores produtivos/insumos locais. Nessa direção, demonstra-se a seguir que a ação pública específica para a agricultura familiar tem priorizado o referencial produtivista, em contradição com aquele agroecológico.

\section{O referencial produtivista no Pronaf e SEAF: limites à agroecologia}

As políticas públicas específicas para a agricultura familiar abriram novas possibilidades para contemplar diferentes categorias sociais de agricultores. Criado na década de 1990, o Pronaf constitui-se na principal ação pública direcionada à agricultura familiar. Contudo, enquanto aumenta o montante de recursos direcionados à agricultura familiar, persiste a dificuldade de incluir o público mais descapitalizado, que representa a maior parcela dos potenciais beneficiários. A isso se soma a alocação de recursos concentrada em número reduzido de atividades, sendo que em 2010 a criação animal, milho, soja e café absorvem cerca de $75 \%$ dos recursos nacionais do custeio. Entende-se que essa exclusão de agricultores e atividades está associada às ideias produtivistas incorporadas ao crédito rural, direcionado aos agricultores familiares "aptos" ao processo modernizante convencional (Schneider et al., 2004; Sabourin, 2007; Souza et 
al., 2013; Petersen, 2013; Grisa et al., 2014; Cazella et al., 2015), assim como a uma base especializada de produção, a qual restringe a diversidade de atividades.

Em síntese, o Pronaf oferece crédito rural subsidiado para o agricultor buscar nos mercados algo que ele não utilizava (dispensava) e/ou substitutos àquilo que ele mesmo produzia. Quando esse processo se intensifica, amplia-se o risco diante das oscilações de mercado e ambientais. Para oferecer segurança econômica à agricultura familiar e aos agentes financeiros envolvidos quanto ao risco de não retorno dos recursos oriundos do Pronaf, foram criadas duas políticas públicas complementares: a) o Programa de Garantia de Preços da Agricultura Familiar (PGPAF), que assegura um preço mínimo à produção financiada ${ }^{23}$; e b) o SEAF, que oferece cobertura (segurança) diante de frustrações de safra por fatores ambientais ou sanitários sem métodos de controle. Enquanto uma parcela minoritária de agricultores familiares brasileiros utiliza as políticas públicas para intensificar o uso de insumos convencionais, a maior parte dessa categoria social não tem acesso ao Pronaf e, consequentemente, ao PGPAF e ao SEAF, o que restringe os resultados sociais dessas políticas públicas (Búrigo et al., 2015).

Operacionalizado em conjunto com o Pronaf, o SEAF incorpora os ideais produtivistas e reproduz a exclusão verificada no crédito rural tradicional. Mesmo com significativos avanços nos últimos anos, apenas cerca de $10 \%$ dos EF do país acessam continuamente a modalidade do Pronaf custeio agrícola - que representa a forma de acesso ao $\operatorname{SEAF}^{24}$ (Souza et al., 2013; Búrigo et al., 2015). Ao oferecer cobertura diante dos riscos de sinistros, o SEAF assume papel similar ao desempenhado pelo seguro agrícola vigente durante a "modernização conservadora" ou "dolorosa" (Graziano da Silva, 1982; Delgado, 1985; Pires, 2009). No passado, o então Programa de Garantia da Atividade Agropecuária (Proagro) direcionava recursos do tesouro para viabilizar o pagamento dos financiamentos agropecuários modernizantes, em anos de frustração de safra.

Ao constituir-se em referencial setorial dominante na ação pública, a maior parte dos mediadores de políticas públicas agropecuárias tem como prioridade direcionar recursos públicos para apoiar e viabilizar a integração de agricultores aos mercados de insumos industriais, com foco na modernização tecnológica voltada ao aumento de produtividade. A expressão desse referencial encontra-se na fala de um profissional técnico de uma grande cooperativa de produção:

Quando eu comecei a trabalhar, há sete anos, quem produzia 130 ou 140 [sacas ha- ${ }^{1}$ ] era bom. Hoje nós temos produtores aqui de 217, 220 sacas ha ${ }^{-1}$ de milho. Então ele está se tecnificando e procurando informação. Fazendo a coisa certinha (OP 12).

Embora os dados empíricos mostrem que produzir mais nem sempre é melhor, esse referencial foi incorporado em políticas públicas brasileiras elaboradas a partir de meados dos anos 1990, com o propósito de beneficiar de forma específica a categoria de agricultores familiares (Grisa, 2012; Grisa et al., 2014). O SEAF foi criado em 2003 e reproduziu normas do Proagro e do Pronaf, visto

\footnotetext{
${ }^{23}$ Articulada ao Pronaf, o PGPAF gera um desconto no pagamento do financiamento quando o governo constata que o preço de mercado do produto agrícola é inferior ao mínimo estabelecido.

${ }^{24} \mathrm{O}$ número de estabelecimentos familiares recenseados em 2006 foi de 4.367.902. Naquele ano, o número total de CPFs que acessaram contratos de Pronaf crédito foi 1.476.807 (33,8\%), reduzindo-se para 1.154.613 em 2013 (26,43\%). Nesse mesmo período, o número de CPFs de beneficiários do custeio agrícola caiu, respectivamente, de 646.315 (14,8\%) para 341.406 (7,8\%) (Búrigo et al., 2015).
} 
que sua operacionalização ocorre junto ao crédito rural de custeio agrícola liberado por esse último (Vasconcelos, 2012).

Mais recentemente têm-se alterado algumas normas e formulado novas políticas públicas ${ }^{25}$ que incorporam referenciais diferentes. Nos casos do Pronaf e do SEAF, a partir da Safra 2012/13, as normas passaram a permitir o financiamento e a cobertura de variedades tradicionais e de insumos da própria unidade produtiva, os quais têm grande importância na produção orgânica (Darolt, 2013). Até essa safra, a obrigatoriedade de apresentar notas fiscais da compra de insumos ou contratação de serviços era pré-requisito para obter a cobertura do SEAF. Em ausência de comprovação, os insumos próprios e o trabalho familiar eram considerados desprovidos de valor quando das perdas, o que limitava o uso do SEAF pelos agricultores orgânicos.

Eu planto orgânico. Ai, se der seca, eu não ganho... [Não ganha seguro?] Não ganho seguro. Por que precisa ter a nota. Até o ano retrasado eu plantei duas bolsinhas só, desse outro que não é orgânico, para fazer silagem. Daquele lá eu ganhei [indenização do seguro]. E do meu que eu tinha plantado [orgânico], mais três bolsinhas, eu não ganhei. [E o senhor fez dois financiamentos?] Não, fiz só um.[...] [E eles exigiam a nota?] É, exigem a nota de compra no mercado,[...] e dai a gente não tem.[...]. [E a perda foi grande?] Sim, era para dar uns três mil $[\mathrm{kg}]$ a mais. E deu mil e seiscentos só (EF 31).

A alteração normativa para o Plano Safra 2012/13 permitiu o financiamento e o seguro de insumos provenientes da unidade produtiva - desde que constem no projeto técnico. Esse avanço entre os mediadores profissionais (formuladores) não repercute diretamente na sua adoção entre os mediadores administrativos (operadores dessas políticas públicas), reflexo de um conflito de referenciais (Muller, 2013) e da lentidão nos processos de mudança institucional. Além disso, os potenciais tomadores nem sempre conseguem fazer valer seus direitos junto ao setor financeiro, reflexo de fragilidades institucionais e estruturais na operacionalização de políticas públicas de crédito rural (Búrigo, 2010).

Em complemento, a partir do Plano Safra 2012/13, as normas do SEAF passaram a prever uma indenização de $65 \%$ da Receita Líquida Esperada (RLE) para a cultura financiada (garantia de renda mínima). A RLE é justificada por dois argumentos principais: a) auxílio à reprodução social das famílias em anos de frustração de safra; e b) seguro aos insumos próprios sem necessidade de comprovantes fiscais ou projeto detalhado. Contudo, a indenização referente à RLE ficou limitada pelo menor valor entre a) um teto por família e b) o valor financiado (geralmente contratado só para os insumos externos). $\mathrm{O}$ teto por agricultor impede a cobertura pelo SEAF quando do uso expressivo de insumos próprios e/ou restringe as iniciativas à pequena escala. Já o limite pelo valor financiado, que deixa de existir a partir de $1^{\circ}$ de janeiro 2015, se opunha à produção com baixos custos. Ou seja, essa indenização contribuiu com a manutenção das famílias em situações críticas, mas pouco valoriza os recursos locais.

Ao estudarmos a ação pública no universo empírico da agricultura familiar do Oeste catarinense, a análise de diferentes sistemas produtivos de milho

\footnotetext{
${ }^{25}$ Como exemplos, destacam-se o Programa de Aquisição de Alimentos (PAA), o Programa Nacional de Alimentação Escolar (PNAE), a Política Nacional de Agroecologia e Produção Orgânica (PNAPO) e a Política Nacional de Assistência Técnica e Extensão Rural (PNATER). Além de dar preferência aos produtos da agricultura familiar e a alimentos orgânicos, o PAA paga "preço premium" 30\% superior aos produtos orgânicos (Schmitt \& Grisa, 2013). Já a PNATER propõe-se a orientar-se pela agroecologia.
} 
permitiu apontar a crescente intensificação no uso de insumos e dos custos de produção. Quando da ausência do SEAF, as perdas de safras nos anos de escassez hídrica, principal sinistro ambiental incidente na região, comprometem o retorno econômico e tendem a desestimular a intensificação produtiva. Ao reduzir os custos financeiros e externalizar os riscos econômicos, o Pronaf e o SEAF contribuem para a adoção de sistemas mais intensivos. Com o repasse dos custos das frustrações de safra para a sociedade, os sistemas produtivos deixam de ser planejados para sofrer menor incidência de perdas quando dos eventos de escassez hídrica.

Assim como verificado por Vasconcelos (2012), enquanto os agricultores convencionais, em geral, se sentem protegidos pelo SEAF para adotar sistemas intensivos, os agricultores orgânicos relatam não conseguir acessar essa política pública.

Do jeito que está hoje... Se tu pegares oito anos atrás, quando nós começamos na agroecologia, era mais vantagem plantar agroecológico que convencional. [Por quê?] Porque sobraria mais, no caso. Hoje, se tu pegares e olhar bem, é mais vantagem tu plantar convencional que agroecológico. Os caras estão plantando, ganhando Proagro. Aí paga a conta no banco, sobra dinheiro e assim vai indo. Agora se a gente plantar e der uma seca, perde tudo. [...] A gente vai ali à comunidade. Eles não se preocupam, porque se der mal, eles vão ganhar. [...]. Eles estão plantando, mas eles estão botando na terra sabendo que está seguro. E já a gente... (EF 36)

Para reduzir os custos de transação e atrair clientes, nem sempre as agências financeiras exigem o envolvimento de agentes de Assistência Técnica e Extensão Rural nos financiamentos de custeio. Mesmo quando há elaboração de projetos, os técnicos responsáveis, em geral, seguem planilhas padrões (pacotes tecnológicos), o que restringe as possibilidades de escolha dos agricultores. Ou seja, restringem sua ação a enquadrar os agricultores na planilha do pacote A ou B, segundo as expectativas de produtividade, que indicam o montante de recursos a ser liberado para a compra de insumos convencionais. Ao desconsiderarem as especificidades relacionadas à unidade produtiva, essas planilhas não especificam nos projetos as quantidades e custos dos insumos próprios que, assim, deixam de ter a cobertura do seguro. Como relata um profissional técnico que assessora produtores orgânicos:

Todos os insumos, você tem que provar que comprou. Esse para mim é o primeiro furo. Em um sistema orgânico de produção, você tem que provar que usou um sistema produtivo que garante produtividade.[...] A planilha para mim é o principal nó. A planilha tem que ser aberta. O meu sistema é uma coisa, o do fulano, do vizinho é outro e do outro é outra, para a mesma cultura. Esse parâmetro que é difícil de estabelecer. O banco tem que ter flexibilidade para aceitar a planilha. Cada projeto é um projeto particular.[...] [A existência do seguro altera a forma de eles fazerem a produção?] Altera, porque eles ficam altamente encaixotados (OP 16).

No Plano Nacional de Agroecologia e Produção Orgânica criado em 2013, a Câmara Interministerial de Agroecologia e Produção Orgânica reconhece os limites operacionais nas linhas do Pronaf orientadas para a agroecologia e produção orgânica:

[...] o sistema financeiro ainda não absorveu as particularidades desses sistemas produtivos. Os projetos de financiamento - custeio e investimento - continuam a ser elaborados tendo por referência custos e receitas dos pacotes tecnológicos, insumos químicos e maquinários utilizados em monoculturas, e as planilhas definidas pelo sistema financeiro, que determinam a configuração dos projetos, necessitam de adequação para a complexidade dos projetos agroecológicos e orgânicos (CIAPO, 2013, p. 25).

O Planapo considera "um grande desafio para as políticas de crédito e seguro a realização de ajus- 
tes no seu marco operacional para o pleno reconhecimento das tecnologias utilizadas nos sistemas de produção orgânica e de base agroecológica" (CIAPO, 2013, p. 26). Contudo, o Planapo 2013-2015 não aponta quais são esses ajustes e somente reforça as possibilidades de acesso às linhas do Pronaf Agroecologia, Floresta e Eco, bem como as linhas Pronaf Mulher e Jovem. Essas linhas de crédito rural apresentam como um de seus diferenciais as taxas de juros inferiores, mas ainda seguem as normas gerais do Pronaf tradicional ${ }^{26}$. Em relação ao SEAF, embora a dificuldade dos agricultores orgânicos seja conseguir acessar a cobertura do seguro quando das perdas, o Planapo prevê somente a possibilidade de uma subvenção $20 \%$ superior em relação às culturas convencionais, a partir da safra 2012/13 (CIAPO, 2013), porém se desconhece qualquer registro de operacionalização dessa previsão.

A agroecologia propõe a intensificação no uso de conhecimentos, diversificação e valorização de processos ecológicos com a utilização de insumos internos e externos de baixo custo. Contudo, em oposição à diversificação, os contratos de crédito rural são elaborados por cultura e não para o conjunto da unidade produtiva, seguindo o pressuposto da escala produtiva baseada na monocultura. Mantidas as regras produtivistas atuais, a diversificação da produção exigiria a elaboração de muitos projetos de pequeno valor, elevando os custos de transação. Como exemplo, um agricultor que produz para vender em feiras tem como objetivo a diversificação da produção para ampliar as possibilidades de venda. A elaboração de vários projetos de pequeno porte não é aceita pelas agências financeiras. Como verificado por Capellesso (2010), agricultores do litoral catarinense foram induzidos a financiar uma cultura (alface em monocultura) para acessar o recurso que seria aplicado em várias culturas (hortigranjeiros). A aparente solução, que garantiu o acesso ao Pronaf, repercutiu na perda de cobertura do SEAF diante do sinistro de granizo. Na ausência da cultura financiada (alface), não há como demonstrar as perdas, visto que a diversificação não condiz com o contrato.

\section{Considerações finais}

A análise de políticas públicas para a agricultura brasileira permite verificar a existência de um conflito de referenciais setoriais. Entre esses há o predomínio de concepções orientadas à integração aos mercados de insumos convencionais. Como demonstra Delgado (1985), os complexos agroindustriais se apropriaram de fases produtivas, contribuindo para a penetração do referencial global capitalista na agropecuária. A grande mudança propiciada pelas políticas públicas específicas está associada à forte penetração desse referencial produtivista entre setores da agricultura familiar, criando um dualismo entre os paradigmas tecnológicos da agricultura convencional e da agroecologia. Ao exacerbar a dualidade ${ }^{27}$ inicial e estimular predominantemente o polo convencional, concluímos que a ação pública tem limitado a adoção da agroecologia enquanto paradigma tecnológico - entendido como base para a criação de processos mais sustentáveis de desenvolvimento rural.

\footnotetext{
${ }^{26}$ Em ausência de dados do Pronaf Agroecologia, o PLANAPO alude para 25 mil contratos e aplicação de R\$260 milhões (CIAPO, 2013 ). Esse montante é baixo quando comparado à expressão da agricultura familiar e pode ser atribuído ao uso de outras linhas do Pronaf e à limitada capacidade (pública e privada) de elaboração de projetos de financiamento destinados à produção orgânica e agroecológica.

${ }^{27}$ Conceitualmente, enquanto o dualismo pressupõe a existência de polos estanques, a dualidade considera que entre esses polos existe um continuum com múltiplos níveis intermediários.
} 
Na medida em que a intensificação produtiva se aprofunda, importantes práticas que garantiam a sustentabilidade da reprodução social de um número significativo de famílias de agricultores são aos poucos abandonadas. Como verificado no estudo de caso com a produção de milho, a intensificação produtiva permite a ampliação da escala e da produtividade, mas não eleva necessariamente a rentabilidade por área. Essa intensificação é dependente de recursos públicos e energia fóssil, apresentando baixa eficiência energética e econômica. A adoção de políticas públicas claramente orientadas pela intensificação produtiva vem de encontro à incorporação do referencial agroecológico e demais elementos ligados à valorização dos recursos locais.

Em uma região com forte presença da ação pública produtivista, constata-se a gradativa reconfiguração das unidades familiares nesta perspectiva. Seja sob o paradigma produtivista ou da agroecologia, os agricultores familiares podem se modernizar e adotar procedimentos mais empresariais. O que fica como questão é compreender a intencionalidade das políticas públicas: a) orientar a ampliação da escala e da produtividade das unidades de produção, com sistemas produtivos dependentes de insumos externos, na perspectiva de uma produção máxima? ou b) considerar o aproveitamento dos recursos locais, incorporando na análise as variáveis rentabilidade por área e sustentabilidade ambiental, na perspectiva de uma produção ótima? ${ }^{28}$ As políticas públicas voltadas ao produtivismo, além de induzirem a um modelo dependente de fatores externos, contribuem para a integração de um segmento minoritário da agricultura familiar brasileira aos mercados, viabilizando a aquisição de insumos com baixo custo financeiro e externalizando riscos ambientais (especialmente escassez hídrica) e sanitários (pragas e doenças sem métodos de controle). Ao analisar os sistemas de produção de milho e leite no Extremo Oeste catarinense, verifica-se que os agricultores tomam decisões sobre os sistemas produtivos levando em consideração as condições de mercado e as oportunidades geradas pelas políticas públicas. Se essas duas dimensões apresentam tendência homogeneizante, elementos internos às unidades produtivas contribuiriam para a persistência da diversidade produtiva no seio da agricultura familiar. Parte dos agricultores familiares pode buscar alternativas às contradições dos mercados competitivos em relações sociais comunitárias, redução do uso de insumos, pluriatividade, reaproximação com a natureza e nos mercados de proximidade. Contudo, essas possibilidades ainda são pouco valorizadas nas políticas públicas específicas de crédito rural e seguro agrícola para a agricultura familiar (Ploeg, 2006; Capellesso et al., 2016).

Ao propor uma reaproximação do agricultor com a natureza, diminuindo sua dependência dos mercados convencionais de insumos, a agroecologia valoriza recursos locais deixados de lado pela agricultura convencional. No contexto brasileiro, há uma persistente exclusão do crédito rural e do seguro agrícola por parte importante da agricultura familiar. Quando esta exclusão é superada, tais políticas se dirigem a uma abordagem produtivista, para as quais aparecem como contraponto o PNAPO e o PLANAPO, que representam esforços no sentido de uma abordagem agroecológica, apesar de sua timidez operacional. Seu grande desafio é superar o recorte social e técnico das políticas públicas convencionais, gerando formas de crédito e seguro que valorizem os recursos locais da agricultura familiar.

${ }^{28}$ A distinção entre produção máxima e ótima é proposta por Altieri (1989). 


\section{Referências}

Almeida, J. Agroecologia: paradigma para tempos futuros ou resistência para o tempo presente? Desenvolvimento e Meio Ambiente, 6, 29-40, 2002. doi: 10.5380/dma. v6i0.22126

Altieri, M. A. Agroecologia: as bases científicas da agricultura alternativa. 2. ed. Rio de Janeiro: PTA- FASE, 1989.

Bonilla, J. A. Fundamentos da Agricultura Ecológica: sobrevivência e qualidade de vida. São Paulo: Nobel, 1992.

Brasil. Lei n. 10.831, de 23 de dezembro de 2003. Dispõe sobre a agricultura orgânica e dá outras providências. Brasília: DOU de 24/12/2003.

Brasil. Lei n. 11.326, de 26 de julho de 2006. Estabelece as diretrizes para a formulação da Política Nacional da Agricultura Familiar e Empreendimentos Familiares Rurais. Brasília: DOU de 25/07/2006.

Brasil. Lei n. 12.512, de 14 de outubro de 2011. Institui o Programa de Apoio à Conservação Ambiental e o Programa de Fomento às Atividades Produtivas Rurais; altera as Leis $\mathrm{n}^{\mathrm{o}} \mathrm{s} 10.696$, de 2 de julho de 2003, 10.836, de 9 de janeiro de 2004, e 11.326, de 24 de julho de 2006. Brasília: DOU de 17/10/2011.

Búrigo, F. L. Finanças e solidariedade: cooperativismo de crédito rural solidário no Brasil. Chapecó: Argos, 2010.

Búrigo, F. L.et al. A. Evolução do Pronaf crédito no período 1996-2013: redimensionando o acesso pelos cadastros de pessoa física. In: Anais do $53^{\circ}$ Congresso da Sober. João Pessoa, 26 a 29 de jul. 2015.

Capellesso, A. J. Os sistemas de financiamento na pesca artesanal: um estudo de caso no litoral Centro-Sul catarinense. Florianópolis, Dissertação (Mestrado em Agroecossistemas) - UFSC, 2010.

Capellesso, A. J.; Cazella, A. A. Indicador de sustentabilidade dos agroecossistemas: estudo de caso em áreas de cultivo de milho. Ciência Rural, 43(12), 2297-2303, 2013. DOI: $10.1590 / \mathrm{S} 0103-84782013005000130$

Capellesso, A. J.; Cazella, A. A. Entre a especialização produtiva e a agroecologia: estratégias de reprodução social de agricultores familiares da Região Extremo Oeste Cata- rinense. Sustentabilidade em Debate, 6(2), p. 33-50, 2015. DOI: $10.18472 \% 2 F S u s t D e b . v 6 n 2.2015 .15492$

Capellesso, A. J. et al. Economic and environmental impacts of production intensification in agriculture: comparing transgenic, conventional and agroecological maize crops. Agroecology and Sustainable Food Systems, 40(3), 215236, 2016. DOI: 10.1080/21683565.2015.1128508

Caporal, F. R.; Costabeber, J. A. Análise multidimensional da sustentabilidade: uma proposta metodológica a partir da Agroecologia. Agroecologia e Desenvolvimento Rural Sustentável, 3(3), 70-85, 2002.

Caporal, F. R.; Costabeber, J. A. Agroecologia e extensão rural: contribuições para a promoção do Desenvolvimento Rural Sustentável. Brasília: MDA/SAF/DATER - IICA, 2004.

Caporal, F. R. et al. Agroecologia: matriz disciplinar ou novo paradigma para o desenvolvimento rural sustentável. Brasília - DF, abril de 2006. 25 p. Disponível em: <http:// www.seaembu.org/docs/agroecologia2.pdf $>$.

Cazella, A. A. et al. Politiques publiques de développement rural au Brésil: le dilemme entre l'inclusion productive et l'aide sociale. In: 52éme Colloque ASDRLF, Montpellier, 7 a 9 jul., 2015.

CIAPO. Brasil Agroecológico: Plano Nacional de Agroecologia e Produção Orgânica - PLANAPO. Brasília: MDA, 2013. Disponível em: <http:/www.mda.gov.br/sitemda/ sites/sitemda/files/user_img_19/BrasilAgroecologico_Baixar.pdf>.

Darolt, M. R. Circuitos curtos de comercialização de alimentos ecológicos: reconectando produtores e consumidores. In: Niederle, P. A.; Almeida, L. de; Vezzani, F. (Orgs.). Agroecologia: práticas, mercados e políticas para uma nova agricultura. Curitiba: Kairós, 2013. p. 139-170.

Delgado, G. C. Capital financeiro e agricultura no Brasil: 1965-1985. São Paulo: Editora da Unicamp, 1985.

Do Carmo, M. S. A produção familiar como locus ideal da agricultura sustentável. In: Ferreira, A. D. D.; Brandenburg, A. (Org.). Para pensar outra agricultura. Curitiba: Ed. UFPR, 1998.p. 215-238. 
Gliessman, S. R. Agroecologia: processos ecológicos em agricultura sustentável. Tradução de Maria José Guazzelli. Porto Alegre: UFRGS, 2000.

Gliessman, S. R. et al. Agroecología: promoviendo una transición hacia la sostenibilidad. Ecossistemas, 16(1), 1223, 2007. Disponível em: <http://www.revistaecosistemas. net/index.php/ecosistemas/article/download/134/131>.

Graziano da Silva, J. A modernização dolorosa: estrutura agrária, fronteira agrícola e trabalhadores rurais no Brasil. Rio de Janeiro: Zahar, 1982.

Grisa, C. Políticas públicas para a agricultura familiar no Brasil: produção e institucionalização das ideias. Rio de Janeiro, Tese (Doutorado em Desenvolvimento, Agricultura e Sociedade) - UFRRJ, 2012.

Grisa, C. et al. Revisitando o Pronaf: velhos questionamentos, novas interpretações. RESR, 52(2), 323-345, 2014. DOI: 10.1590/S0103-20032014000200007

Hall, P. A.; Taylor, R. C. R. As três versões do neoinstitucionalismo. Lua Nova, 58, 193-224, 2003.

Howard, Sir A. Um testamento agrícola. São Paulo: Expressão Popular, 2007.

IBGE. Censo Agropecuário 2006: Brasil, Grandes Regiões e Unidades da Federação. Rio de Janeiro: IBGE, 2009.

Lorenzon, J. Impactos sociais, econômicos e produtivos das tecnologias de produção de leite preconizadas para o oeste de Santa Catarina: estudo de caso. Florianópolis, Dissertação (Mestrado em Agroecossistemas) - UFSC,2004

Mazoyer, M.; Roudart, L. História das agriculturas no mundo: do neolítico à crise contemporânea. Tradução de Cláudia F. Falluh Balduino Ferreira. São Paulo: Editora UNESP; Brasília, DF: NEAD, 2010.

Muller, P. L'analyse cognitive de politiques publiques: vers une sociologie politique de l'acion publique. Revue Française de Science Politique, 50(2), 189-208, 2000. DOI: 10.3406/rfsp.2000.395464

Muller, P. Les politiques publiques. 10éd. Paris: PUF, 2013.

Navarro, Z. Agroecologia: as coisas em seu lugar (A agronomia brasileira visita a terra dos duendes). ColóquioRevista do Desenvolvimento Regional, 10(1), 11-45, 2013. Disponível em: <http://seer.faccat.br/index.php/coloquio/ article/view/23/pdf_11>.
Odum, E. P. Ecologia. Rio de Janeiro: Guanabara Koogan S.A., 1988.

Palier, B.; Surel, Y. Les “trois i”et l'analyse de l'état em action. Revue Française de Science Polítique, 55(1), 7-32, 2005. DOI: $10.3917 / \mathrm{rfsp} .551 .0007$

Petersen, P.Agroecologia e a superação do paradigma da modernização. In: Niederle, P. A.; Almeida, L. de; Vezzani, F. (Orgs.). Agroecologia: práticas, mercados e políticas para uma nova agricultura. Curitiba: Kairós, 2013.p. 69-103.

Pimentel, D. et al. Environmental, energetic, and economic comparisons of organic and conventional farming systems. BioScience, 55(7), 573-582, 2005. DOI: 10.1641/0006-3568(2005)055[0573:EEAECO]2.0.CO;2

Pires, M. J. de S. O termo modernização conservadora: sua origem e utilização no Brasil. Revista Econômica do Nordeste, 40(3), 411-424, 2009. Disponível em: <http://www. bnb.gov.br/projwebren/exec/artigoRenPDF.aspx?cd_artigo_ren $=1140$ >

Ploeg, J. D. van der. O modo de produção camponês revisitado. In: Schneider, S. (Org.). A diversidade da agricultura familiar. Porto Alegre: Ed. UFRGS, 2006.p. 13-54.

Ploeg, J. D. van der. Camponeses e impérios alimentares: lutas por autonomia e sustentabilidade na era da globalização. Porto Alegre: UFRGS, 2008.

Primavesi, A. Agroecologia: ecosfera, tecnosfera e agricultura. São Paulo: Nobel, 1997.

Sabourin, E. Que política pública para a agricultura familiar no segundo governo Lula? Sociedade \& Estado, 22(3), 715-751, 2007. Disponível em: <http://www.scielo.br/pdf/ se/v22n3/09.pdf $>$.

Schmitt, C. J.; Grisa, C. Agroecologia, mercados e políticas públicas: uma análise a partir dos instrumentos de ação governamental. In: Niederle, P. A.; Almeida, L. de; Vezzani, F. (Orgs.). Agroecologia: práticas, mercados e políticas para uma nova agricultura. Curitiba: Kairós, 2013.p. 215-265.

Schneider, S. et al. Histórico, caracterização e dinâmica recente do Pronaf - Programa Nacional de Fortalecimento da Agricultura Familiar. In: Schneider, S.; Silva, M. K.; Marques, P. E. M. (Orgs.). Políticas públicas e participação social no Brasil rural. Porto Alegre: UFRGS, 2004.p. 237-254. 
Schultz, T. W. A transformação da agricultura tradicional. Tradução de J. C. Teixeira Rocha. Rio de Janeiro: Zahar, 1965.

Souza, P. M. de et al.Análise da evolução do valor dos financiamentos do Pronaf-Crédito (1999-2010): número, valor médio e localização geográfica dos contratos. RESR, 51(2), 237-254, 2013. DOI: $10.1590 / \mathrm{S} 0103-20032014000200007$

Surel, Y. Chronique - Idées, intérêts, institutions dans l'analyse des politiques publiques. Pouvoirs, Revue Française d'Études Constitutionnelles et Politiques, 87 (L'extrême droite en Europe), 161-178, 1998. Disponível em: <http:// www.revue-pouvoirs.fr/IMG/pdf/87Pouvoirs p161-178 chroniques_analyse_politiques_publiques.pdf $>$.
Vasconcelos, J. M. M. Seguro da agricultura familiar (SEAF): história, implementação e desafios em Francisco Beltrão (PR). Brasília, Dissertação (Mestrado em Agronegócios) - UnB, 2012.

Veiga, J. E. da. Desenvolvimento sustentável: o desafio do Século XXI. Rio de Janeiro: Garamond, 2010.

Wilkinson, J. Mercados, redes e valores: o novo mundo da agricultura familiar. Porto Alegre: EdUFRGS, 2008.

Zukowski, J. C. Seguro da Agricultura Familiar. Palestra com apresentação eletrônica do Ministério do Desenvolvimento Agrário. In: Reunião técnica sobre o Seguro da Agricultura Familiar. Chapecó, 28 de novembro de 2012. 